\title{
International Marketing Study of Textile Products under the Export Strategies to COMESA
}

\author{
Eng. Mohamed M El Hosainy, Dr.Abla Kamal El Din, and Dr.Tamer Farouk Khalifa \\ Faculty of Applied Arts, Textile and Weaving Department
}

Helwan University

Egypt

\begin{abstract}
Manufacturing textiles and readymade garments have always been important to Egypt's economy, especially considering the marketing strategies used by composite apparel manufacturers. There is also potential for the implementation of the Common Market for Eastern and Southern Africa (COMESA) \& Continental Free Trade Area (CFTA) agreements with small and medium firms in Egypt.

The objective of this study is to develop and formulate effective electronic commerce marketing and export strategies for the textile and apparel sector.

In comparison to traditional commerce, e-commerce allows the user to search online, compare prices of required products and order merchandise from a single platform. Businesses in developing countries are able to access global markets more easily by using B2B e-commerce to increase the use of e-commerce. Research indicates that e-commerce is important for Egypt and other African countries, highlighting the significance of the field for business applications.

Egypt and Africa also have an excellent opportunity to grow manufacturing exports and become the world's next great manufacturing centre as industries depart from China and move to low-cost regions.

After thorough analysis, we have developed policies for the development of textile and garment industries in Egypt in order to formulate and execute it has two major objectives to produce quality products in line with international standards, and also to boost the textile industry in Egypt with effective electronics commerce marketing strategies for cultivating market growth. It consist mainly single web based electronic platform where buyers and sellers come together to sell their raw material and finished textile products.
\end{abstract}

Small and medium apparel and textile businesses can use the findings from this research to formulate and implement effective marketing strategies to pursue market growth.

Key Words: COMESA, E-Commerce, Marketing Strategy, Textile Industries.

\section{INTRODUCTION}

The continent of Africa poses the greatest potential for Egyptian exports. Based on historical and political ties, historians and economists support the assertion that textiles and ready-to-wear have great opportunities to access this market. As a member of the COMESA Economic Gathering, Egypt opens the door to the African markets and introduces the Egyptian private sector to them and assists them in identifying the needs and consumer tastes in them and pursuing business opportunities there. Egypt and African countries exchange relatively little trade, and more communication and effort is needed, particularly on the part of the private sector, to improve the situation. At a time when China, India, Turkey and Israel are competing for the African market, the African market has long been undervalued. 
A large amount of attention is paid by the government to the textile and ready-made garment industries. This is because this sector is important strategically, economically, and agriculturally, Although, most of the pioneers of this industry in Egypt have deviated from the administrative science system and its amazing evolution. Developments, innovation, and continuous success are the characteristics of sciences that have made it a permanent standout in any industry, based on the condition that it is serious and effective in the various tools, strategies, and systems of this science to ensure it is a pivotal part of that establishment. Now, it is crucial that we expand our vision to embrace the role of marketing in this industry, which never disappears, as a step forward to build a future that is comprehensive as well as deep.

As researchers, we consider it our duty to communicate methods of applying marketing science to small and medium enterprises in the field of textiles and fashion in order to gain a larger market share for Egyptian products.

Studying how textile products are marketed to foreign markets in light of export strategies is an important study in an economically developed country. The challenges faced by textile factories are no longer primarily technical issues, but are rather primarily administrative problems. In order to determine the consumer need, the most important step is to study the target markets to produce items that fulfil that need and are affordable.

Textile industry success is not anymore primarily determined by technical, engineering, and invention aspects after these aspects have achieved a high level of development. But it depends on the country's ability to market its products and study new market opportunities are also crucial.

\section{RESEARCH PROBLEM}

Insufficient care and support are provided to small and medium textile enterprises. In order to support these projects, we must set a strategy for manufacturing and production in light of marketing strategies, especially for African markets.

COMESA has been relatively understudied when it comes to marketing textile products \& The textile industry isn't making good use of the agreement between COMESA and the Common Market for Eastern and Southern Africa.

\section{RESEARCH IMPORTANCE}

To implement one of the advanced marketing studies and strategies for medium and small businesses, thereby raising living standards and helping to accelerate economic development.

In the textile and clothing industry, Egypt has a distinct comparative advantage that makes it able to expand into new markets like those in Africa.

\subsection{Research Aims}

1) Identifying the problems facing the marketing of textile products for small and medium enterprises in light of the new economic changes.

2) Conducting a marketing study of the African market in question.

3) Awareness of the importance of electronic commerce marketing strategy in the field of textiles and clothing.

4) Activating trade relations, consolidating the relationship with the African continent, and benefiting from the Common Market for Eastern and Southern Africa - COMESA agreement.

\section{RESEARCH METHODOLOGY}

1) Applying marketing science and its modern mechanisms to increase export output and open new markets.

2) Paying attention to the African market and activating economic agreements will have repercussions on the Egyptian economy and national security.

3) Encouraging and assisting small and medium enterprises, increasing national income and eliminating unemployment.

4) Applying the role of science and technology to increase the world class quality production of textile materials.

5) Case study of E commerce single platform. 


\section{CONCLUSION}

E Commerce platform and digital marketing strategies will improve the present scenario of the Egypt textile industry. Currently, the textile sector faces many problems that have contributed to the economic crisis in Egypt. These problems such as,

- A number of Egyptian companies have employed foreign labour, particularly Chinese and Indian labour, because of the lack of qualified workers and improper training in the Egyptian industry.

- There is a mismatch between the agricultural and industrial sectors: the agriculture sector provides a high-quality cotton, and the industrial sector begins to use a low-quality cotton with low prices, so it began to import cotton.

- Cotton prices are high due to the adoption of free trade policies since 1994, which makes textile inputs more expensive, resulting in a decreasing decline in production and India's decision to ban cotton exports, which consequently causes cotton prices to increase.

- Subsidies provided to their competitors in India limit the competition abilities of the industrial sectors.

- Increasingly more Synthetic fibres and Polyester yarns are being used in textile production instead of cotton due to the characteristics of these materials that include colour stability, strength, durability, low prices, etc., which resulted in the increase in their imports.

- Textile prices have increased because of the high input costs caused by high interest rates on bank loans, the increase in fuel prices, and high sales taxes on capital equipment, which limit a firm's ability to modernize its production lines.

In Egypt, there are numerous employment opportunities in the textile sector that help solve the unemployment problem. In addition to textile product manufacturing, several complementary industries provide the textile industry with raw materials or use its products. Government statistics show that almost one-third of the total manufacturing job openings in Egypt are in the textile industry. As a result, the cost of labour in Egypt is considered an advantage for investors, as it is considered to have among the lowest labour costs in the world.

Despite being the third-largest industrial sector in Egypt after the chemicals and food sectors, the textile industry is considered the engine of the economy. Egypt is the largest exporter of textiles and clothing to the United States from Africa and the second largest from the Mediterranean. Cotton and textile exports represent $40 \%$ of non-oil exports in Egypt, making them the second most important source of foreign currency in the country after oil exports.

Policy decisions by governments have significantly impacted the structure and competitiveness of the textile industry. Trade and import policies are formulated to protect this industry because of its significance impact on the national economy and its important role in solving the unemployment problem in Egypt. Although, some Egyptian public companies are privatized in order to increase their efficiency and to function in a market-oriented way. Nevertheless, some large companies, such as Misr Textile Company and other strategic companies, will remain under government control.

COVID-19 pandemic and the related disruption of economic activity in Egypt have been handled well by the country's implementation of proactive measures to address health and social needs as well as support sectors directly impacted by the crisis. Thus far, the growth slowdown has proven less drastic than expected, with Egypt ranked among the few countries in the world with a positive growth rate. As per the IMF, Egypt remains the largest economy in the Arab world. However, there are still risks to the outlook, including that a second wave of the pandemic may result in a slower pace of recovery domestically and globally. As per the IMF, Egypt remains the largest economy in the Arab world. However, there are still risks to the outlook, including that a third wave of the pandemic may result in a slower pace of recovery domestically and globally.

Economic conditions in Egypt are expected to improve going forward. With the country's real GDP growth forecast to be 2.8\% in FY 2021, the country is one of the few to see positive growth in 2020. All sectors will recover modestly except tourism, which is likely to take much longer to recover. Global travel disruptions are expected to last throughout the year. Although there remain risks to the outlook, they include another round of COVID-19, less favourable financing conditions for emerging economies, and a drop in remittances.

The inflation rate is expected to be $6.2 \%$ in 2021 and an average rate of $7.4 \%$ over the next five years. Thus, over the medium term, there is less threat of significantly elevated inflation, thus alleviating monetary policy pressure. Nonetheless, the Central Bank of Egypt should continue to consider multiple trade-offs and their price impacts when developing monetary policy to anchor inflation within its target range. Due to Egypt's foreign exchange reserves and access to domestic and external debt markets, it should be able to meet its external and fiscal financing needs and maturities in the coming year. 
In spite of the high exposure to financing shocks, Egypt's credit metrics are relatively resilient, in part due to policy credibility and effectiveness, which can exert a positive influence on its financial position. Providing the rating agencies with a longer track record of credible and effective fiscal, economic and debt management, a marked improvement in debt affordability and reduced gross financing needs would probably lead to an upgrade in the medium term. It would also be beneficial to see signs of a sustained improvement on the labour market and in non-hydrocarbon exports, since this would signal a higher degree of competitiveness and thus increase Egypt's ability to absorb shocks.

It is important to consider strengths and challenges when assessing the outlook for Egypt. Strengths actually revolve around the country's large and diversified economy. Several factors contribute to a country's ability to combat the pandemic: a track record of reform commitment and implementation, a large domestic funding base, and overseas reserves that surpass foreign debt payments over the next year and provide buffers against significant capital outflows from emerging markets. Aside from this, primary budget surpluses have been restored and are expected to remain. There are a number of challenges, including high government debt, low debt affordability, and very large refinancing needs, as well as social pressure from an unemployed youth population and lingering political event risks.

Diversification, both conventional and unconventional, is a key strength for the Egyptian economy. It also creates multiple investment opportunities across multiple sectors, increasing the economy's ability to absorb both internal and external shocks.

Logistic is the main concern whenever we are planning for the implementation of the E- commerce platform. Supply chains, distribution plays a crucial role in the success of a number of operations within the logistics system. Egypt has a global proximity to the global market, Because of its unique geographic location, the Suez Canal is Egypt's shortest link between east and west. Each year, the Suez Canal carries about $8 \%$ of the world's maritime traffic. Transits between east and west or west to east through the canal result in significant cost and distance savings.

Based on the above information it can be concluded that E commerce and digital marketing strategies will be very much effective for the Egypt textile industry to spread int COMESA region. E commerce will be the battle field for the for researching the wider market in geographical, demographic and ideological term. With better social media presence and increased customer attraction, ecommerce can increase sales and boost revenues. New tools, strategies, and technologies, as well as an increasing number of companies, assist customers in making decisions more easily. Consumers will learn more about offers and prices in order to get the most out of their experience.

\section{RESULTS}

Following were the major finding of this research project with respect to the SWOT analysis mentioned in the method.

Strengths

1) The present scenario of Egypt with regards to the textile industry is in par with developed Asian Nations (*). Most of the MSME textile industries get benefited from the support of EGYPT government COMESA agreement. In year 2020 there are ___ registered MSME textile industries and are large scale Textile industries which can play an important role in the import economy.

2) The textile industries is facilitated by many supporting industries which owned a huge stock of raw material such as cotton, jute, silk, wool raw silk and synthetic goods. However they are well established but their industrialization is very slow. Increased production of these raw materials reflects the promotion of textile industries in the Egypt.

3) Egypt holds a name for tourism industry across the world. This excellence came various famous tourist destinations (e.g. Museums, Historical monuments UNESCO heritage sites etc). This image can be a bonus for even in the textile products , to compete in the international market. Quality may be promoted to gain the competitive advantage over other textile producing countires.

4) Labour law prevalent in Egypt are favourable to workers and most of them are in compliance with international labour law $(*)$. The government carefully monitors the well-being of the working sector. Child labour is not used in manufacturing process like in other developing African countries. This makes Egypt an ethical manufacturer.

5) Egypt is strategically located in close proximity to major sea and air tracks. As a results time consumed for logistics will be less compared to other landlocked African countries like Central Africa ,Zambia and Zimbabwe . Since the competitions is tough for fashion oriented textile products in American and Europeans countries but Egypt has an advantage to export Egypt's traditional textile material to the developed countries apart from that Egypt can export all kinds of textile products to other African countries and other Asian market due to logistic support under COMESA agreement. 
6) The textile industries are supported by established garment manufacturing machine industry. This industry caters for the need of the garment manufacturing plants in Egypt . This industry can be considered as fully complementing the local textile industry making the whole industry self-sufficient at present level of technology.

\section{WEAKNESS}

1) Egyptian textile and garment manufacturer are lagging behind in application of standard techniques for maintenance, quality control, process planning and testing etc. because of the competition of prices. Even the large scale manufacturers in the local context have not implemented these procedures. Considering global trends, effective procedure such as TPM (Total Productive Maintenance) and quality product such as TQM (Total Quality Management ) are common.

2) Product development in textile industry is virtually non-existent compared to the international textile companies. MSME sector cannot focus much on this aspect because of financial constraints. Even though, product development is important for continuous improvement, even the large scale manufacturers are reluctant to focus on product development.

3) Local manufacturers are not interested in getting feedback from the customers for products they put in the market. The communication between the marketing and production department is poor. This may lead to failure in identifying customer preferences. Hence local textile and garment manufacturer has not been able to achieve customer satisfaction. As a consequence, not only local customers but also global consumers accepted textile products from internationally accredited textile industries from western and European developed countries. Also, lots of designs have failed to achieve the target marketing benchmark.

4) The facilities for training in the textile and garment industry in Egypt are minimal. This is because of lack of training institutions. There are only few training centre under Egypt government and private sectors. Due to lack of facilities and available resources, The number of participants for the offered training courses are low.

5) In order to get the best output from the production process, the raw material should be good in the quality. Due to lack of laboratory facility for textile industry, especially for raw material testing, quality testing and for research and development. Egyptian manufacturer find it difficult to keep up with the global quality standards.

6) Institutions that are established for the development of textile Industry are not independent. Financial barriers are encountered when carrying out activities for the betterment of industry.

7) Financial institution are not flexible enough to assist the local industries to find the necessary finance to expand the business. The interest rate and the bank guarantee are beyond the reach of the local manufacturer. The SME sector finds it difficult to keep up with the ever improving technology because of lack of financial assistance from banks even if they are capable of using the technology.

8) Egyptian textile industry suffers from negative attitude of the public toward locally manufactured products. Machinery manufacturer also face this problem. Even though the level of quality is matched with international standards.

9) Technological Knowledge present in textile industry is minimal in the local textile industry. It has made this industry backward that uses primitive machinery and production technique.

\section{RECOMMENDATION}

Egypt is party to the following regional agreements: Agadir Agreement, COMESA Agreement, European Union-Egypt Association Agreement, GAFTA, Egypt-Turkey Free Trade Agreement, and numerous free and preferential trade agreements with individual Arab countries.

Any organization in the textile and garment industry has been shaped by three factors: insertion in to global markets, contemporary link with the social structure and intervention through government policies. As per the recommendation of COMESA Agreement Egypt may form independent and autonomous Co-operative societies for the development of textile industries, marketing agency \& raw resource material. Government of Egypt can play important role in textile and garment industry by determining the nature of export orientation program and formulating policies to tailor production primarily toward the international market.

In this research after extensive review we have formulated the polices for the development of textile and garment industry in Egypt. It has a two major objective how to achieve the quality product as per international norm and another is the e commerce digital marketing strategies which will play an important role to boost the textile industry in the Egypt.

\section{Vision}

1) Formulation of autonomous organization or institute owned by government of Egypt which will run E- commerce website \& Mobile app exclusively for the promotion of business to business textile and apparel market.

2) E commerce website will contain two division Digital Learning for Capacity building and digital marketing platform. 
3) This E-Commerce website will work to expand the marketing area of Egypt textile and apparel industry from domestic market to the international market.

4) Institute and or organization will work to register all Egypt's small medium and large-scale textile industries (Including raw material suppliers and finished products manufacturers) in this platform.

5) Institute or Organization can charge annual from the registered industry to run the platform.

6) Providing a single platform to all seller and buyer from textile industries to discover everything about the textile industry at a one place.

\section{Objective}

\subsection{Digital Learning for Capacity building}

Digital learning can be provided by forming an expert group from the Egypt textile industries, Research Institutes and global consultants. Autonomous Institute or an Organization will formulate a digital learning platform on the same E commerce website in the form of published articles, Video, Documentaries, Regulatory guidelines with regards to various trade acts such as COMESA, GATT, Import Export Policies, Live questions and answers, Consultancies about the production of textile raw materials \& finished textile products as per the international guideline with the following mentioned objectives. Digital learning and capacity building of textile industry can attract all sellers and buyers on this single E commerce Platform.

1.1.1. Assisting the textile industry take its place at the forefront of the manufacture and export of clothing

1.1.2. Energize both Remote Coordinate Speculation as well as enquire about and growth inside the segment by empowering the industry to build world-class state-of-the-art manufacturing capabilities in accordance with natural measurements

1.1.3. Equip industry to resist import penetration pressures and maintain a dominant presence on the domestic market.

1.1.4. Change controls and directives so that the textile industry's various segments can operate in a more competitive environment.

1.1.5. Energize both Remote Coordinate Speculation as well as enquire about and growth inside the segment by empowering the industry to build world-class state-of-the-art manufacturing capabilities in accordance with natural measurements.

1.1.6. Develop a strong multi-fibre base with thrust of product upgradation and diversification.

1.1.7. Maintain and improve the weavers' and craftspeople's traditional knowledge, skills, and talents.

1.1.8. Improve human asset aptitudes and capabilities, with extraordinary accentuation on those working within the decentralized segments of the Industry; and renew the Organization structure.

1.1.9. Extend profitable work by empowering the development of the industry, with specific exertion coordinated to improving the benefits to the inaccessible zones of Egypt.

1.1.10. Make Data Innovation (IT), an fundamentally portion of the whole esteem chain of material generation and thereby encourage the industry to realize worldwide measures in terms of quality, plan and marketing.

1.1.11. Include and guarantee the dynamic co-operation and association of the State Governments, Financial Institutions, Business people, Agriculturists and Non-Governmental Associations within the fulfillment of these goals

1.1.12. Awareness about the advancement of sectors such as

1.1.12.1. Innovative up gradation

1.1.12.2. Improvement of Efficiency

1.1.12.3. Quality Awareness

1.1.12.4. Fortifying of the crude material base

1.1.12.5. Product Enhancement

1.1.12.6. Increase in trades and inventive promoting techniques

1.1.12.7. Financing arrangements

1.1.12.8. Expanding employment openings

1.1.12.9. Human Resource Advancement

1.1.13 Implement vigorously, in a time bound manner, the Technology Upgradation covering all manufacturing segments and raw materials of the industry such as, Cotton, Jute, Silk, Handlooms, Spinning and Weaving Sectors.

COVID 19 and much big E commercial organization from across the world has taught us that it is no longer necessary to go physically in the store to purchase or sell anything. A consumer purchase habits is changes from traditional store 
to online shopping. This platform will exclusively work for Business to Business sellers and buyers. It will allow sales move from a direct channel to a web enabled sales process that will allow consumers to perform transaction by electronic means.

It will create a huge marketing opportunity for Egypt textile industry across the African and Middle East countries.

Structure of E Commerce Digital Platform

1) Website

Website is the backbone of the E commerce platform. All the information is displayed on the website. It should be accessible from all browsers and mobile phones

2) Product Catalogue

This is the one more important section where all the product details, description, specification, photographs , availability, date of delivery, Stock details, price rate will be mention.

3) Shopping Cart

This is the function or a software in the website which enable to add the products in the cart. This function allows consumer to select, review and purchase the product

4) Payment Gateway

This feature enable consumers to purchase the product from any part of the world with the help of internet facility and secure online fund transaction.

5) Order Tracking

This feature enables consumers to track the order and its logistic information, delivery of the products

6) Customer Support

This feature enable consumers to support all kind of queries regarding E Commerce platform.

Strategies for the development of successful digital marketing single platform

1) Website design should be well organized and simple to understand by the all international consumers, website should contain graphics, navigation search which enables to search the website's all information effectively.

2) Registration of Textile Industries in the E Commerce Platform All kind of large, small and medium textile industries should participate to register themselves in the E commerce platform. However, government can encourage them to register. As all procedure is online so it will be very easy to every one to register in this platform. Government should charge a nominal fee for this registration.

3) All the registered textile industries from Egypt can display their products details in the form of catalogue. Detailed content about the photograph with high quality images of all product should be displayed. Detailed description of the product should mentioned to understand each and every details of the products.

4) Sellers information details such as history, achievements, company profile contacts details are necessary to include to gain the trust of the buyers.

5) Logistic support all sellers should be tied up with logistic service providers to transport their products across the world with a suitable software. However it should has a facility that consumer can track it with real time update of the tracking information.

6) Realtime updates facility should be provided in the E Commerce website to enable sellers to update their inventory stock in real time manner.

7) E Payment Gateway is the facility which enables buy any product online from any part of the world. E Commerce website should be connected with the secure online transaction with latest updated online transaction technology.

8) Data analysis of all product is mandatory to upgrade the website time to time.

9) Consumer feedback is a part of quality assurance which enable E Commerce organization to launch new features according to the need of buyers and Sellers.

\section{REFERANCES}

1. Blyth,J(2005) Essentials of marketing (3rd edition) hallow essex, England: person .education limited.

2. Capon, N \& capon, R (2009).managing marketing in 21st century-European edition Bronville, New York USA:wessex,Inc..,.

3. Davidson. H., \& Keegan, W, J (2004).offensive marketing: an action guide to gaining competitive advantage .Burlington,MA, USA-Butterworth-Heinemann.

4. Gereffi, G. (1999). International trade and industrial upgrading in the apparel commodity chain. Journal of International Economics, 
5. Joarder, M., Nurul, A. K. M., Hakim, M. M. (2010), "Post-MFA Performance of Bangladesh Apparel Sector", International Review of Business Research Papers

6. Kotler, P. (2000) Marketing Management, 10th edition, Prentice-Hall, Englewood Cliffs, NJ.

7. Pringle, H. (2004), Celebrity Sells, John Wiley and Sons, Chichester.

8. Fashion Marketing Third Edition Edited by Mike Easy

9. Brassington, F. and Pettitt, S. (2006), Principles of Marketing, 4th Edition, Financial Times/Prentice Hall, London.

10. Jones, R. (2006), The Apparel Industry, 2nd Revised Edition, Blackwell Publishing, Oxford.

11. Tungate, M. (2005), Fashion Brands: Branding Style from Armani to Zara, Kogan Page Ltd, London.

12. Baker, M.J. (2007), Marketing Management and Strategy, 4th Revised Edition, Palgrave MacMillan, Basingstoke. Edition, Palgrave MacMillan, Basingstoke.

13. Hines, T. and Bruce, M. (2001), Fashion Marketing: Contemporary Issues, Butterworth-Heinemann, Oxford.

14. Solomon, M.R. (2007), Consumer Behavior: Buying, Having, and Being, Prentice Hall, Harlow.

15. Kotler, P. (2000), Marketing Management: The Millennium Edition, Prentice Hall, Englewood Cliffs, NJ.

16. Proctor, T. (2000), Essentials of Marketing Research, Pearson Education Limited, Harlow.

17. Hague, P. (2003), Marketing Research: A Guide to Planning Methodology and Evaluation, 3rd Edition, Kogan-Page Limited, London.

18. Cahill, D.J. (2006), Lifestyle Market Segmentation (Haworth Series in Segmented, Targeted, and Customized Market), Haworth Press Inc., New York.

19. Cova, B. et al. (eds) (2007), Consumer Tribes, Butterworth- Heinemann, London.

20. Dibb, S. and Simkin, L. (2007), Market Segmentation Success: Making

21. It Happen, Haworth Press Inc., New York. International Thomson Business Press, London.

22. Elliot, R. and Percy, L. (2006), Strategic Brand Management, Oxford University Press, Oxford.

23. Baker, M.J. and Hart, S. (2007), Product Strategy and Management, 2nd Edition, FT Prentice Hall, London.

24. Baker, M.J. (2007), Marketing Strategy and Management, 4th Edition, Palgrave Macmillan, Basingstoke.

25. Dibb, S. and Simkin, L. (2008), Marketing Planning: A Workbook for Managers, Thomson Learning, London.

26. Kotler, P. and Armstrong, G. (2008), Principles of Marketing, 12th Edition, Pearson/Prentice Hall, Harlow.

27. Gilligan, C. and Wilson, R.M.S. (2003), Strategic Marketing Planning, Butterworth-Heinemann, Oxford.

28. H Mintzberg, JA Waters - Strategic management journal, 1985

29. O’Regan, N. and Ghobadian, A. (2005) Innovation in SMEs

30. AI El-Ansary - European business review, 2006

31. Tapscott \& Williams (2006) 'ideagoras' or marketplaces of ideas 